Johnson \& Wales University ScholarsArchive@JWU

Health \& Wellness Department Faculty

Publications and Research

College of Health \& Wellness

2017

\title{
Public healthcare funding modifies the effect of out-of-pocket spending on maternal, infant, and child mortality
}

Jonathan K. Noel

Johnson \& Wales University - Providence, Jonathan.Noel@jwu.edu

Follow this and additional works at: https://scholarsarchive.jwu.edu/health_fac

Part of the Medicine and Health Sciences Commons

\section{Repository Citation}

Noel, Jonathan K., "Public healthcare funding modifies the effect of out-of-pocket spending on maternal, infant, and child mortality" (2017). Health \& Wellness Department Faculty Publications and Research. 47.

https://scholarsarchive.jwu.edu/health_fac/47 


\section{Public health care funding modifies the effect of out-of-pocket spending on maternal, infant, and child mortality}

Jonathan K. Noel

To cite this article: Jonathan K. Noel (2017) Public health care funding modifies the effect of outof-pocket spending on maternal, infant, and child mortality, Health Care for Women International, 38:3, 253-266, DOI: 10.1080/07399332.2016.1254217

To link to this article: https://doi.org/10.1080/07399332.2016.1254217

View supplementary material $₫$

Accepted author version posted online: 31

Oct 2016.

Published online: 29 Dec 2016.

Submit your article to this journal $\widetilde{ }$

Llll Article views: 133

View Crossmark data \lceil 


\title{
Public health care funding modifies the effect of out-of- pocket spending on maternal, infant, and child mortality
}

\author{
Jonathan K. Noel \\ Department of Community Medicine and Health Care, University of Connecticut School of Medicine, \\ Farmington, Connecticut, USA
}

\begin{abstract}
Increased out-of-pocket (OOP) health care spending has been associated with increased maternal, infant, and child mortality, but the effect of public health care spending on mortality has not been studied. I identified a statistically significant interaction between public health care expenditure and OOP health care spending for maternal, infant, and child mortality. Generally, increases in public expenditure coincide with decreased rates of mortality, regardless of OOP spending levels. Specifically, higher levels of public expenditure with moderate levels of OOP spending may result in the lowest mortality rates. Increased public health care spending may improve health outcomes better than efforts to reduce OOP expenditure alone.
\end{abstract}

\section{ARTICLE HISTORY}

Received 27 January 2015

Accepted 25 October 2016

\section{Introduction}

Maternal, infant, and child mortality remain significant public health issues, particularly in the developing world. Among 289,000 maternal deaths worldwide in 2013, 286,000 occurred in developing countries (World Health Organization [WHO], 2014), and up to two-thirds of infant newborn deaths and more than half of all deaths among children under 5 are preventable with effective health measures (World Health Organization, 2012; World Health Organization, 2014). Other researchers have noted that systematic structural changes to health care systems, such as increased construction of government run health care facilities, have decreased mortality rates, but few studies have focused on the effect of out-ofpocket (OOP) spending (Liljestrand \& Sambath, 2012). The WHO has previously stated the reducing required OOP spending is a key step toward universal health care access and, ultimately, better health outcomes (Evans, Elovainio, \& Humphreys, 2010).

CONTACT Jonathan K. Noel jknoel@hotmail.com E Department of Community Medicine and Health Care, University of Connecticut School of Medicine, 263 Farmington Avenue, MC 6325, Farmington, CT 06030-6325, USA. Color versions of one or more of the figures in the article can be found online at www.tandfonline.com/uhcw. 
Consisting of official payments made directly to health care providers and institutions (i.e., direct payments), charges for services that are intended to be free (i.e., informal payments), and transportation, housing and food-related costs (i.e., indirect costs), OOP spending is considered the primary financial barrier to accessing health care, particularly in low- and middle-income countries such as Tanzania (2015 GDP per capita $=$ US\$865) and Serbia (2015 GDP per capita $=$ US\$5,144) (World Health Organization, 2010; Arsenijevic, Pavlova, \& Groot, 2014; Saksena et al., 2010). Leading categories of OOP spending include food, transportation, and pharmaceuticals, with transportation costs contributing up to $50 \%$ of total OOP expenses in developing countries, such as Tanzania (Kruk, Mbaruku, Rockers, \& Galea, 2008; Saksena et al., 2010). In Canada, food and travel costs comprise up to three-quarters of OOP spending associated with childhood cancer treatment (Tsimicalis et al., 2013). OOP spending at the point of service is also relatively common. In Kenya, Burkina Faso, and Tanzania, 98\%, 92\%, and 91\% of women paid OOP costs for care during childbirth, respectively, and in Nigeria, $95 \%$ of individuals financed malaria treatments through OOP spending (Onwujekwe et al., 2010; Perkins et al., 2009). Moreover, the presence of a government-run health care system may not obviate the need for OOP spending. In India, 80\% of 9,643 households financed maternal health services OOP due to inadequate public health care facilities (Leone, James, \& Padmadas, 2013).

The extent of OOP spending varies by country (Figure 1) and condition. In the United States, mean OOP spending on asthma medication was estimated to be (in 2010 US\$) \$154 per year for children aged 5-18 years old between 1997 and 2007, while OOP spending for children with influenza can exceed (in 2009 US\$) \$1,400 per occurrence for children requiring hospitalization (Karaca-Mandic, Jena, Joyce, \& Goldman, 2012; Ortega-Sanchez et al., 2012). In the United Kingdom, families of children diagnosed with Autism Spectrum Disorder (ASD) spent (in 2007 U. K.£) approximately $£ 500$ per month in direct costs and lost wages in 2006 and 2007, and mean annual OOP spending (in 2011 US\$) for children with ASD in Israel was \$8,288 in 2010 and 2011 (Barret et al., 2012; Raz, Lerner-Geva, Leon, Chodick, \& Gabis, 2013). High OOP spending ( $<20 \%$ of disposable income) can result in large proportions of family income being consumed by health care costs. For example, childhood hospitalization in India can cost $178 \%$ of mean monthly household income (Srivastava, Awasthi, \& Agarwal, 2009). Likewise, vaginal delivery costs in Pakistan can exceed $56 \%$ of monthly income, and $121 \%$ of monthly income can be spent for cesarean delivery (Khan \& Zaman, 2010). OOP health care spending has also been identified as a leading cause of financial bankruptcy in the United States (Himmelstein, Thorne, Warren, \& Woolhandler, 2009).

The amount of OOP health care spending is inversely related to health care utilization, following the Law of Demand, which is a basic microeconomic concept that states that consumer demand increases or decreases as price decreases or increases, respectively (Hildenbrand, 1983). In China, increased OOP spending was associated with decreased maternal health care utilization, and financial 
difficulties are the primary reason for at-home births (Gao, Barclay, Kildea, Hao, \& Belton, 2010; Yuan, Qian, \& Thomsen, 2013). OOP costs have also been associated with delays in receiving care during delivery in Thailand (Sreeramareddy, Sathyanarayana, \& Kumar, 2012). Moreover, nearly one-third of Indian children with diarrhea, fever, and cough may not receive treatment due to OOP costs (Liabsuetrakul \& Oumudee, 2011). Conversely, decreases in OOP costs may increase health care utilization. In addition, following the law of demand, Vietnam's Health Care Fund for the Poor has increased health care utilization by reducing OOP costs, and programs in Bangladesh, China, India, Laos, and the United States have achieved similar results (Axelson, Bales, Minh, Ekman, \& Gerdtham, 2009; Devadasan et al., 2010; Douangvichit, Liabsuetrakul, \& McNeil, 2012; Galbraith et al., 2012; Gopalan \& Durairaj, 2012; Kullgren et al., 2010; Long, Zhang, Xu, Tang, \& Hemminki, 2010; Nguyen et al., 2012; Figure 1).

Decreases in health care utilization, in turn, likely decrease health outcomes. Previously, researchers calculated odds ratios (OR) from aggregated, country-level data that demonstrated that OOP spending as a percent of total health expenditure (THE) may be a statistically significant predictor of maternal (OR $[95 \% \mathrm{CI}]=1.32$ $[1.04,1.66])$, infant (OR $[95 \% \mathrm{CI}]=1.60[1.28,2.01])$, and child (OR $[95 \%$ $\mathrm{CI}]=1.64[1.28,2.10]$ ) mortality (Muldoon et al., 2011). However, the effect of the public health care spending in each country on mortality was not investigated. Here, I sought to determine if the type of health care system utilized moderates the effect of OOP costs on country-level maternal, infant, and child mortality rates using publicly available data from the WHO and the World Bank. Such an analysis has not been performed before. The primary hypothesis is that there is an inverse relationship between the rate of public funding as a percent of health care spending and the rate of maternal, infant, and child mortality. A secondary hypothesis is that there is a direct relationship between OOP costs and mortality rates, regardless of public funding levels.

\section{Methods}

\section{Data}

The independent variables of interest were OOP spending as a percent of THE and public health care expenditure (PHE) as a percent of THE. OOP spending as a percent of THE is defined by the WHO as "expenditure on health by households as direct payments, discretionary" (World Health Organization, 2012). PHE is defined as spending from government agencies, donations from international agencies and nongovernmental organizations, and spending from compulsory health insurance funds, such as Medicare in the United States (World Bank, 2016).

Three dependent variables were used in the analysis: the maternal mortality ratio (deaths per 100,000 live births), the infant mortality rate (deaths per 10,000 live births), and the mortality rate for children aged 1-5 years (deaths 
per 10,000 live births). The maternal mortality ratio and the infant mortality rate were directly measured. The mortality rate for children aged 1-5 years was not directly available; however, an under-5 mortality (deaths per 10,000 live births) was provided for all included countries. The under- 5 mortality rate includes the infant mortality rate, so the mortality rate for children aged 1-5 years was calculated by subtracting the infant mortality rate from the under-5 mortality rate in order to remove the influence of the infant mortality rate on the mortality rate of toddlers and preschool aged children. For example, the mortality rate for children aged 1-5 years in Mexico (2.4 deaths per 10,000 live births) was calculated by subtracting the infant mortality rate (14.4 deaths per 10,000 live births) from the under-5 mortality rate (16.8 deaths per $10,000$ live births) (i.e. $16.8 / 10,000-14.4 / 10,000=2.4 / 10,000)$.

Several covariates were included in the analysis. THE per capita (in 2010 US\$) was used to control for health care spending from all sources, and GDP per capita (in 2010 US\$) was included to control for overall country income. Increases in GDP per capita have been associated with decreases in maternal and infant mortality in previous studies (Bradley, Elkins, Herrin, \& Elbel, 2011). Country fertility rates (births per female) were included to control for increased cumulative mortality risk associated with an increased number of pregnancies, and population growth (\%) was included because previous research has indicated that increased population growth is associated with an increase in maternal and child mortality (Sonneveldt, DeCormier Plosky, \& Stover, 2013). Health care access was controlled for using two different covariates contingent on the dependent variable. For maternal mortality, the percent of births attended by skilled health staff, which was defined as personnel with sufficient expertise to supervise, care for, and provide advice to women during pregnancy, labor, and the postpartum period, and who are trained to conduct deliveries and care for newborns independently, was used. For infant mortality and the mortality rate for children aged 1-5 years, the measles vaccination rate (\%) was used as a proxy (Muldoon et al., 2011). Measles vaccination has been part of the WHO and United Nations Children's Fund's Global Immunization Vision and Strategy since 2006 (WHO \& United Nations Children's Fund, 2005).

Data from 2010 were selected for analysis due to data completeness; however, some data substitutions were required. The percent of births attended by skilled health staff was not collected from all countries in 2010. The arithmetic mean between 2006 and 2010 was used instead of the 2010 figure alone. Years prior to 2006 were thought to no longer accurately represent existing conditions of health care access. Only countries with information for all remaining independent and dependent variables were included in the analysis. OOP as a percent of THE was obtained from the WHO's Global Health Expenditure Database (GHED; World Health Organization, 2012). All other data were obtained from the World Banks's World Development Indicators database (World Bank, 2013). 


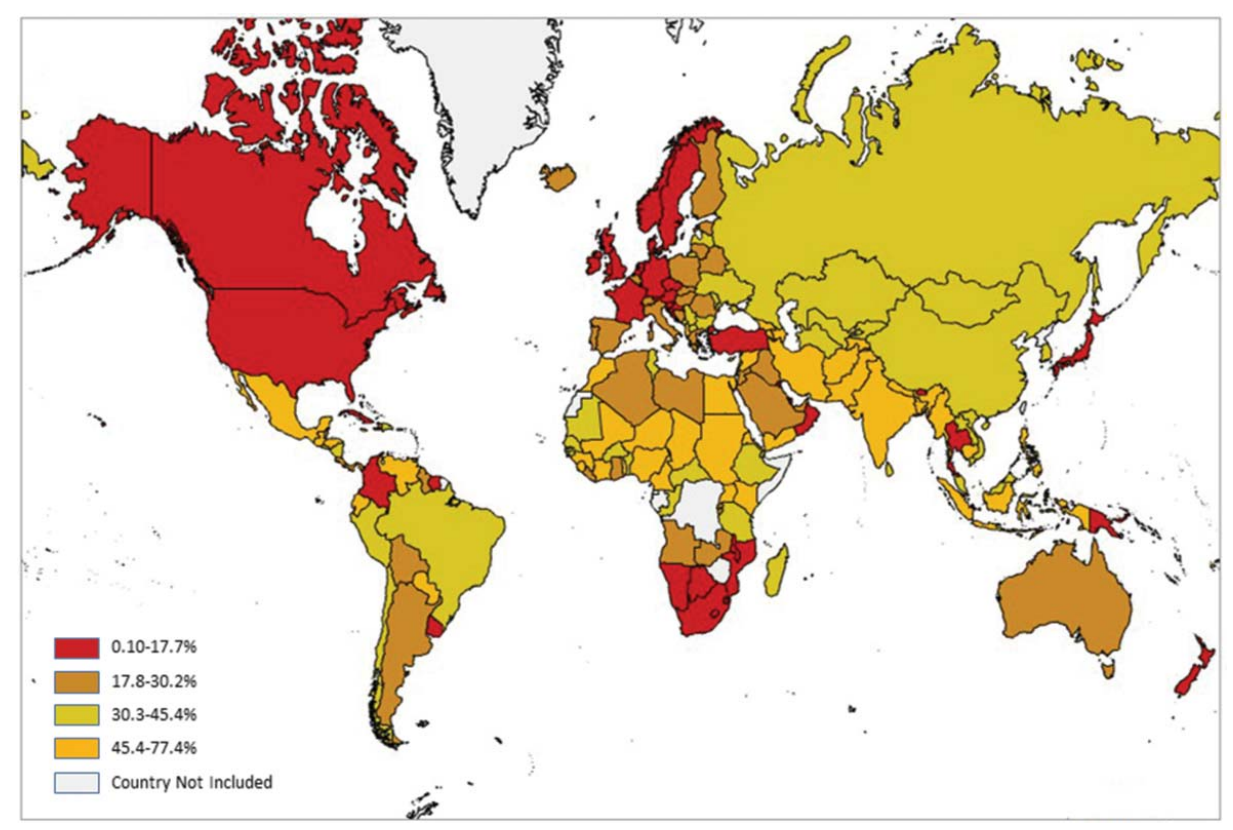

Figure 1. Global distribution of out-of-pocket spending as a percent of total health expenditure (Source: World Health Organization, 2012).

\section{Statistical analysis}

Statistical analysis was performed using IBM SPSS Statistics for Windows, version 21.0 (Armonk, NY, USA). All variables included in the analysis were examined for symmetry, skewness, and kurtosis prior to analysis. Due to high degrees of skewness (i.e., skewness $>1.0$ ) and kurtosis (i.e., kurtosis $>1.0$ ), both primary independent variables and all covariates were condensed into quartiles to eliminate the possibility that the skewed continuous variables could bias the results. The dependent variables, which were the maternal mortality ratio, the infant mortality rate, and the mortality rate for children aged 1-5 years, were maintained as continuous. Generalized linear models specified with a Poisson distribution and a log link function were used to determine the effect of the OOP spending and PHE on each measure of mortality. Wald $\chi^{2}$ values were used to test significance. The interaction between the primary independent variables was included in the models by specifying the OOP spending and PHE interaction in the syntax of the SPSS GENLIN procedure. In cases where this interaction was statistically significant, pairwise comparisons with the Bonferroni correction, used to limit Type I error, were used to determine differences between categories. The principal comparisons were those between countries with high OOP spending and low PHE and countries with low OOP spending and high PHE. The results were also examined for any consistent trends within categories (e.g., decreases in mortality as PHE increases within an OOP spending category). Because SPSS applies the Bonferroni correction by multiplying the uncorrected $p$-value by the number of comparisons, which is 
mathematically equivalent to dividing alpha by the number of comparisons, an alpha level of 0.05 was selected a priori for all significance tests.

The University of Connecticut Health Center Institutional Review Board determined this study was not considered human subjects research.

\section{Results}

Data were available for 173 of the 194 (89.2\%) countries in the GHED. Excluded countries had a statistically significant lower GDP per capita $(p<0.01)$, but no statistically significant differences were detected for any other variable ( $p s>0.1$ ). Using WHO's classification system, there were 49 countries from Europe (28.3\%), 42 from Africa (24.3\%), 32 from the Americas (18.5\%), 21 from the Western Pacific (12.1\%), 19 from the Eastern Mediterranean (11.0\%), and 10 from South-East Asia (5.8\%). There were 33 low-income countries (15.0\%, GDP per capita < \$1,045), 45 lower middle-income countries $(27.7 \%$, GDP per capita $=\$ 1,05-\$ 3,975)$, 48 upper middle-income countries $(26.6 \%$, GDP per capita $=\$ 3,976-\$ 12,275)$, and 47 high-income countries $(30.6 \%$, GDP per capita $>\$ 12,275)$ in the sample.

Median maternal mortality was 65.0 deaths per 100,000 live births, while median infant and mortality for children aged 1-5 years were 164.0 and 27.0 deaths per 10,000 live births, respectively (Table 1). Median PHE as a percent of THE was $58.5 \%$, and median OOP spending as a percent of THE was $30.2 \%$. Figures 1 and 2 show the global distribution of OOP and PHE, respectively. Tables S1 and S2 list the OOP and PHE by country. In 2010 dollars, median GDP and health expenditure per capita were $\$ 4,442$ and $\$ 266$, respectively. Median population growth and fertility rate were $1.3 \%$ and 2.4 births per woman, respectively. Median birth rate attended by skilled health staff was $81.9 \%$, and the median measles vaccination rate was $93.0 \%$.

Results from the generalized linear models are reported in Table 2. For maternal $(p<0.001)$, infant $(p<0.001)$, and children aged $1-5$ mortality $(p<0.001)$, PHE,

Table 1. Descriptive statistics.

\begin{tabular}{lcccc}
\hline & & \multicolumn{3}{c}{ Percentiles } \\
\cline { 3 - 5 } Variable & Mean (SD) & $25 \%$ & $50 \%$ & $75 \%$ \\
\hline Maternal mortality (per 100,000 live births) & $172.8(233.1)$ & 15.5 & 65.0 & 230.0 \\
Infant mortality (per 10,000 live births) & $279.4(256.9)$ & 75.5 & 164.0 & 436.5 \\
Under 5 mortality (per 10,000 live births) & $388.9(410.2)$ & 87.5 & 196.0 & 601.5 \\
Mortality for children aged 1-5 (per 10,000 live births) & $109.5(164.4)$ & 12.5 & 27.0 & 152.5 \\
Public health expenditure (\% of total health expenditure) & $58.1(18.7)$ & 45.3 & 58.5 & 73.9 \\
Out-of-pocket spending (\% of total health expenditure) & $32.9(18.7)$ & 17.7 & 30.2 & 45.4 \\
GDP per capita (US\$) & $12,016(17,573)$ & 1,343 & 4,442 & 13,038 \\
Health expenditure per capita (US\$) & $971(1,713)$ & 75 & 266 & 824 \\
Population growth (\% annual) & $1.5(1.5)$ & 0.5 & 1.3 & 2.3 \\
Fertility rate (births/woman) & $2.9(1.5)$ & 1.8 & 2.4 & 3.8 \\
Births attended by skilled health staff (\%) & $81.9(24.1)$ & 62.8 & 96.6 & 99.8 \\
Measles vaccination rate (\%) & $88.1(12.3)$ & 81.5 & 93.0 & 97.0 \\
\hline
\end{tabular}




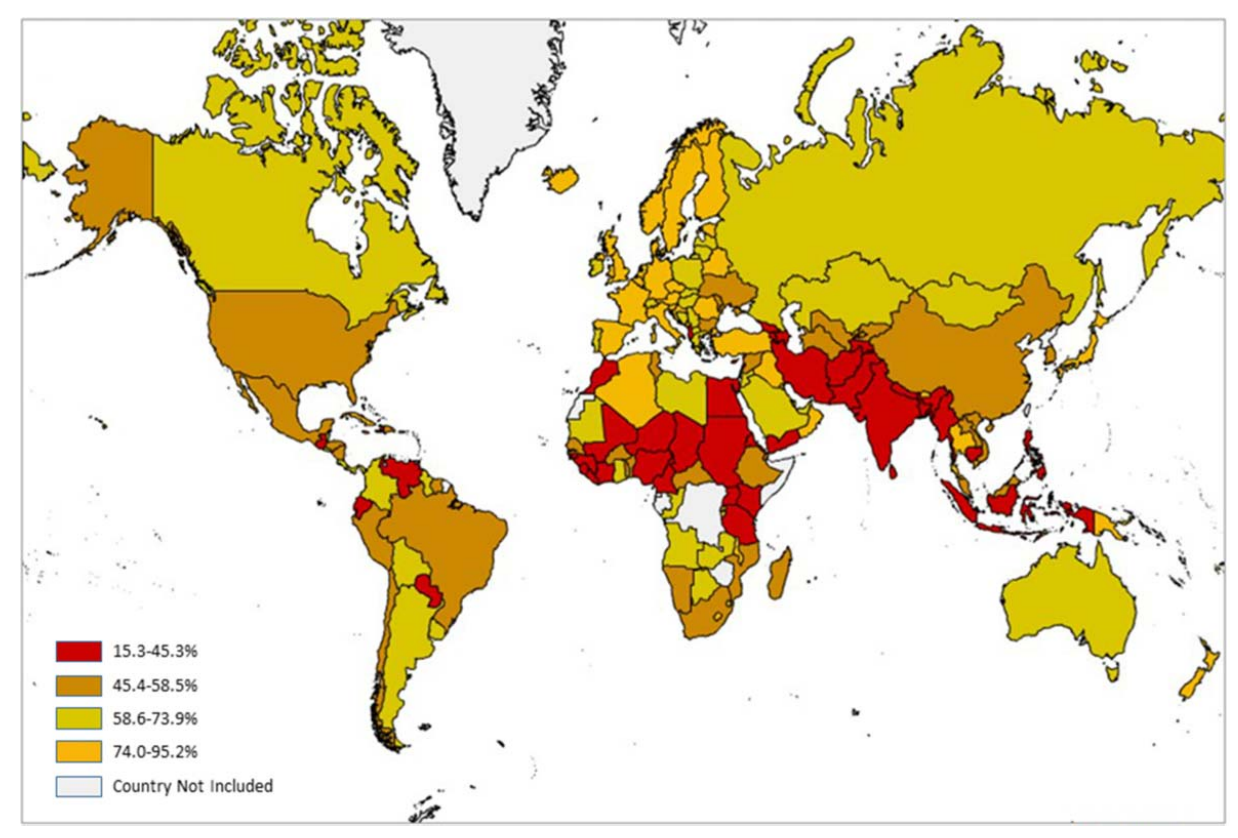

Figure 2. Global distribution of public health expenditure as a percent of total health expenditure (Source: World Bank, 2013).

Table 2. Generalized linear models, effect of public health expenditure and OOP on mortality.

\begin{tabular}{|c|c|c|c|}
\hline Variable & Wald $\chi^{2}$ & $d f$ & $p$ \\
\hline \multicolumn{4}{|l|}{ Maternal mortality } \\
\hline PHE & 500.990 & 3 & $<0.001$ \\
\hline OOP spending & 2349.973 & 3 & $<0.001$ \\
\hline GDP per capita & 533.913 & 3 & $<0.001$ \\
\hline Health expenditure per capita & 178.963 & 3 & $<0.001$ \\
\hline Population growth & 324.200 & 3 & $<0.001$ \\
\hline Fertility rate & 324.225 & 3 & $<0.001$ \\
\hline Births attended by skilled health staff & 316.974 & 3 & $<0.001$ \\
\hline OOP spending * PHE & 230.889 & 5 & $<0.001$ \\
\hline \multicolumn{4}{|l|}{ Infant mortality } \\
\hline PHE & 203.391 & 3 & $<0.001$ \\
\hline OOP spending & 864.862 & 3 & $<0.001$ \\
\hline GDP per capita & 328.071 & 3 & $<0.001$ \\
\hline Health expenditure per capita & 469.344 & 3 & $<0.001$ \\
\hline Population growth & 460.527 & 3 & $<0.001$ \\
\hline Fertility rate & 330.365 & 3 & $<0.001$ \\
\hline Measles vaccination rate & 275.055 & 3 & $<0.001$ \\
\hline OOP spending * PHE & 247.533 & 5 & $<0.001$ \\
\hline \multicolumn{4}{|l|}{ Mortality for children aged $1-5$} \\
\hline PHE & 97.356 & 3 & $<0.001$ \\
\hline OOP spending & 634.269 & 3 & $<0.001$ \\
\hline GDP per capita & 628.289 & 3 & $<0.001$ \\
\hline Health expenditure per capita & 110.241 & 3 & $<0.001$ \\
\hline Population growth & 334.443 & 3 & $<0.001$ \\
\hline Fertility rate & 616.231 & 3 & $<0.001$ \\
\hline Measles vaccination rate & 532.920 & 3 & $<0.001$ \\
\hline OOP spending * PHE & 165.276 & 5 & $<0.001$ \\
\hline
\end{tabular}


Table 3. Estimated marginal means, highest OOP spending/lowest PHE vs. lowest OOP spending/ highest PHE.

\begin{tabular}{lcccc}
\hline Variable & Mean & $95 \% \mathrm{Cl}$ & $d f$ & $p$ \\
\hline Maternal mortality & & & & $<0.001$ \\
$\quad$ Highest OOP spending/lowest PHE & 86.9 & $64.0,89.9$ & 1 & $<0.001$ \\
$\quad$ Lowest OOP spending/highest PHE & 52.9 & $50.4,55.5$ & & \\
Infant mortality & & & 1 & $<0.001$ \\
$\quad$ Highest OOP spending/lowest PHE & 187.3 & $183.3,191.5$ & & \\
$\quad$ Lowest OOP spending/highest PHE & 150.5 & $146.1,155.0$ & & \\
Mortality for children aged 1-5 & 46.6 & $44.6,48.7$ & & \\
$\quad$ Highest OOP spending/lowest PHE & 29.3 & $27.6,31.1$ & & \\
$\quad$ Lowest OOP spending/highest PHE & &
\end{tabular}

OOP spending, and the OOP spending by PHE interaction were statistically significant. All included covariates were also statistically significant ( $p s<0.001)$.

There were no countries categorized in the extreme categories for both primary independent variables (i.e., first or fourth quartile for both OOP spending and PHE). Countries with the highest OOP spending and the lowest PHE had statistically significant higher rates of maternal $(p<0.001)$, infant $(p<0.001)$, and children aged $1-5$ mortality $(p<0.001)$ than countries with the lowest OOP spending and highest PHE (Table 3). For maternal mortality, this difference was approximately 34 deaths per 100,000 live births. For infant and children aged 1-5 mortality, this difference was approximately 36.8 and 17 deaths per 10,000 live births, respectively.

For maternal mortality only, however, the lowest overall rate was within countries in the second quartile of OOP spending and the highest PHE (Table 4). These differences were statistically significant $(p<0.001)$. The highest rate of maternal mortality occurred in countries with the least OOP spending, which were also in the third quartile of PHE.

The rates of infant and children aged 1-5 mortality did not follow the maternal mortality pattern. For the mortality rate for children aged 1-5 years, countries in the highest PHE quartile for each OOP spending quartile consistently had

Table 4. Estimated marginal means, OOP spending by PHE interaction, maternal mortality only.

\begin{tabular}{lccccc}
\hline OOP spending quartile & PHE quartile & Mean & $95 \% \mathrm{Cl}$ & $d f$ & $p$ \\
\hline 4 & 2 & 73.5 & $68.0,79.3$ & 1 & $<0.001$ \\
& 1 & 86.9 & $84.0,89.9$ & 1 & $<0.001$ \\
3 & 3 & 72.0 & $67.4,76.9$ & 1 & $<0.001$ \\
& 2 & 80.4 & $77.4,83.5$ & 1 & $<0.001$ \\
2 & 1 & 65.1 & $60.8,69.7$ & 1 & $<0.001$ \\
& 4 & 40.8 & $36.3,45.8$ & & \\
& 3 & 85.5 & $82.0,89.2$ & 1 & $<0.001$ \\
1 & 2 & 67.0 & $62.3,72.0$ & 1 & $<0.001$ \\
& 2 & 112.0 & $104.6,119.9$ & 1 & $<0.001$ \\
& 4 & 52.9 & $50.4,55.5$ & 1 & $<0.001$ \\
& 3 & 150.0 & $138.8,162.2$ & 1 & $<0.001$ \\
\end{tabular}

${ }^{*}$ Reference category. 
Table 5. Estimated marginal means, OOP spending by PHE interaction, mortality for children aged 1-5 only.

\begin{tabular}{lccccc}
\hline OOP spending quartile & PHE quartile & Mean & $95 \% \mathrm{Cl}$ & $d f$ & $p$ \\
\hline 4 & $2^{*}$ & 37.2 & $33.6,41.3$ & & \\
& 1 & 46.6 & $44.6,48.7$ & 1 & $<0.001$ \\
3 & $3^{*}$ & 34.8 & $31.9,38.0$ & & 0.003 \\
& 2 & 41.4 & $39.4,46.5$ & 1 & 0.003 \\
2 & 1 & 44.0 & $40.4,47.8$ & 1 & $<0.001$ \\
& $4^{*}$ & 29.0 & $25.4,33.2$ & & $<001$ \\
& 3 & 62.7 & $59.5,66.2$ & 1 & 1 \\
1 & 2 & 42.7 & $38.8,47.0$ & 1 & $<0.001$ \\
& 1 & 94.7 & $88.0,101.9$ & 1 & $<0.001$ \\
& $4^{*}$ & 29.3 & $27.6,31.1$ & & $<001$ \\
\hline
\end{tabular}

*Reference category.

statistically significant lower mortality rates than other PHE quartiles ( $p$ s $=0.003$ to $<0.001$; Table 5); however, there was no consistent pattern in mortality rates from lowest to highest PHE quartile. For instance, in the two lowest OOP spending quartiles, the mortality rates for children aged 1-5 years in the third PHE quartile were higher than the mortality rates in the second PHE quartile, with mean differences of 20 and 35.4 deaths per 10,000 live births, respectively. Decreases in the mortality rate for children aged 1-5 years as a function of PHE were noted in the 2 highest OOP spending quartiles, however. Conversely, no statistically significant patterns in infant mortality were noted.

\section{Discussion}

My results suggest, similar to previous findings, that, at the country level, OOP spending is a statistically significant predictor of maternal, infant, and child mortality, and indicate that the effect of OOP spending on mortality may be moderated by country-level PHE. For maternal mortality, the lowest rates observed occurred when a moderate level of OOP spending (second lowest quartile) was combined with high PHE (highest quartile). Lower rates of child mortality were also observed as PHE spending increased, although no discernible patterns existed for infant mortality.

In general, a statistically significant OOP spending by PHE interaction should be expected. Research conducted in Africa and Asia demonstrate that the introduction of publicly funded community and social health insurance schemes improves health care utilization, quality of care, and social inclusions (Odeyemi \& Nixon, 2013; Spaan et al., 2012). In low-income countries, where the gross national income (GNI) per capita is less than US\$1,045, and middle income countries, where the GNI per capita is between US\$1,045 and US\$12,746, the pooling of resources in universal health care programs has increased access to cancer medications, particularly among the most disadvantaged populations (Lopes Gde, de 
Souza, \& Barrios, 2013; World Bank, 2014). Research in Europe has also demonstrated that publicly funded health care systems are more effective at reducing health care access inequalities compared to privately funded systems (Gelormino, Bambra, Spadea, Bellini, \& Costa, 2011).

Increases in health care coverage, access, and utilization in publicly financed systems have translated into improved population health outcomes. Health care coverage without OOP costs provided by the French National Health Insurance System has eliminated disparities in cardiac catheterizations, coronary interventions, and in-hospital mortality (Danchin et al., 2011). Treatment for cardiovascular disease is also considered independent of socioeconomic status in the United Kingdom where equal access to primary treatment options and secondary preventions measures was equal across economic categories (Hawkins et al., 2013). Moreover, findings from Taiwan indicate that geographic health disparities in appendicitis cases have narrowed after the introduction of a national health insurance scheme (Huang, Yip, Chang, \& Chou, 2006), and in the United States, the requirement to purchase health insurance may empower underprivileged groups to seek higher level care, even when disparities in low-level health care access remain (Amri, Stronks, Bordeianou, Sylla, \& Berger, 2014).

The importance of publicly financed health care is underscored by contradictions between macrolevel and microlevel OOP spending on health care outcomes. In Ghana, 2,194 households containing 2,592 children under 5 years old were randomized to either a prepayment scheme group or a fee-for-service practice group (Ansah et al., 2009). Households in the prepayment scheme had significantly greater health care utilization rates, but no differences were detected in moderate anemia, severe anemia, mean hemoglobin concentration, parasite infection, or mortality, which challenges the assumption that the purchase of health insurance will result in health gains via increased health care utilization. In Bangladesh, the Project for Advancing the Health of Newborns and Mothers randomized participants to one of the three study groups: home care, community care, or the control, where existing levels of care were neither enhanced nor economically subsidized (LeFevre et al., 2013). Neonatal deaths were significantly reduced in the home care arm, but that was accompanied by an approximate $12 \%$ increase in OOP health care spending, implying that greater OOP health care expenditure can lead to improved health outcomes in the absence of other forms of health care financing.

Although further supporting research is needed, the inconsistencies between macroeconomic and individual research on the effects of OOP spending indicate that OOP spending may be a poor policy target for improving health outcomes. Efforts at improving regional or national health care structures through publicly financed systems may prove more fruitful, with subsequent decreases in OOP a positive consequence of such a system. However, decreases in OOP spending without increases in publicly financed health care may have little effect on health since there would be no subsequent increase in health care availability. The goal may not be to eliminate OOP health care spending, but to find an appropriate balance 
between OOP spending and PHE. The French health care system may serve as an example, where the public sector finances approximately $75 \%$ of all health care costs, private insurance covers approximately 15\%, and OOP costs cover the remaining 10\% (Mossialos, Wenzl, Osborn, \& Anderson, 2015).

\section{Limitations}

There are several limitations to this study. First, this is a macroeconomic study using country-level, aggregated data. Intracountry differences are masked with this approach, particularly for large, variable countries; causation cannot be determined; and inferences of individual-level effects should not be made. Second, intercountry comparisons may be inappropriate as the WHO and the World Bank have highlighted potential sources of error in data collection, particularly for resourcepoor nations (World Health Organization, 2012). Third, the analysis excludes the impact of private insurance health expenditures, which is the third component of health care financing, on mortality. Fourth, mean values for one covariate were used because of limited data availability, and collapsing continuous variables into categories could have increased Type II error due to loss of information, although this effect likely did not occur. Finally, there may be factors associated with maternal, infant, or under-5 mortality such as the availability of fresh food, presence of clean water, or infectious disease rates that were not included in the analysis.

\section{Conclusions}

Maternal, infant, and child mortality remain significant public health problems. This analysis suggests that country-level OOP spending on health care is associated with maternal, infant, and child mortality; however, this effect may be moderated by country-level PHE. Areas with high PHE and moderate levels of OOP spending appear to have the lowest mortality rates. Programs targeting individual OOP spending as a means to improve health may be ineffective without simultaneous increases in health care availability made possible with increased PHE. Further microlevel and macrolevel research is needed to inform policy makers, health care providers, and public health professionals about the role of OOP spending and PHE on health outcomes.

\section{Acknowledgment}

Dr. Audrey Chapman, Ph.D., M.Div., S.T.M., provided editorial support for this manuscript.

\section{References}

Amri, R., Stronks, K., Bordeianou, L. G., Sylla, P., \& Berger, D. L. (2014). Gender and ethnic disparities in colon cancer presentation and outcomes in a US universal health care setting. Journal of Surgical Oncology, 109(7), 645-651. 
Ansah, E. K., Narh-Bana, S., Asiamah, S., Dzordzordzi, V., Biantey, K., Dickson, K., ... Whitty, C. J. (2009). Effect of removing direct payment for health care on utilisation and health outcomes in Ghanaian children: a randomised controlled trial. PLOS Medicine, 6(1), e1000007.

Arsenijevic, J., Pavlova, M., \& Groot, W. (2014). Out-of-pocket payments for public healthcare services by selected exempted groups in Serbia during the period of post-war healthcare reforms. International Journal of Health Planning and Management, 29(4), 373-398.

Axelson, H., Bales, S., Minh, P. D., Ekman, B., \& Gerdtham, U. G. (2009). Health financing for the poor produces promising short-term effects on utilization and out-of-pocket expenditure: evidence from Vietnam. International Journal for Equity in Health, 8, 20.

Barrett, B., Byford, S., Sharac, J., Hudry, K., Leadbitter, K., Temple, K., ... PACT Consortium. (2012). Service and wider societal costs of very young children with autism in the UK. Journal of Autism and Developmental Disorders, 42(5), 797-804.

Bradley, E. H., Elkins, B. R., Herrin, J., \& Elbel, B. (2011). Health and social services expenditures: associations with health outcomes. BMJ Quality and Safety, 20(10), 826-831.

Danchin, N., Neumann, A., Tuppin, P., De Peretti, C., Weill, A., Ricordeau, P., \& Allemand, H. (2011). Impact of free universal medical coverage on medical care and outcomes in lowincome patients hospitalized for acute myocardial infarction: an analysis from the French National Health Insurance system. Circulation Cardiovascular Quality and Outcomes, 4(6), 619-625,

Devadasan, N., Criel, B., Van Damme, W., Manoharan, S., Sarma, P. S., \& Van der Stuyft, P. (2010). Community health insurance in Gudalur, India, increases access to hospital care. Health Policy and Planning, 25(2), 145-154.

Douangvichit, D., Liabsuetrakul, T., \& McNeil, E. (2012). Health care expenditure for hospitalbased delivery care in Lao PDR. BMC Research Notes, 5, 30.

Evans, D. B., Elovainio, R., \& Humphreys, G. (2010). Health systems financing: The path to universal coverage. Geneva, Switzerland: World Health Organization. Retrieved from: http:// www.who.int/whr/2010/whr10_en.pdf?ua=1

Galbraith, A. A., Soumerai, S. B., Ross-Degnan, D., Rosenthal, M. B., Gay, C., \& Lieu, T. A. (2012). Delayed and forgone care for families with chronic conditions in high-deductible health plans. Journal of General Internal Medicine, 27(9), 1105-1111.

Gao, Y., Barclay, L., Kildea, S., Hao, M., \& Belton S. (2010). Barriers to increasing hospital birth rates in rural Shanxi Province, China. Reproductive Health Matters, 18(36), 35-45.

Gelormino, E., Bambra, C., Spadea, T., Bellini S., \& Costa, G. (2011). The effects of health care reforms on health inequalities: a review and analysis of the European evidence base. International Journal of Health Services, 41(2), 209-230.

Gopalan, S. S., \& Durairaj, V. (2012). Addressing maternal healthcare through demand side financial incentives: experience of Janani Suraksha Yojana program in India. BMC Health Services Research, 12, 319.

Hawkins, N. M., Scholes, S., Bajekal, M., Love, H., O’Flaherty, M., Raine, R., \& Capewell, S. (2013). The UK National Health Service: delivering equitable treatment across the spectrum of coronary disease. Circulation Cardiovascular Quality and Outcomes, 6(2), 208-216.

Hildenbrand, W. (1983). On the "Law of Demand." Econometrica, 51(4), 997-1019.

Himmelstein, D. B., Thorne, D., Warren, E., \& Woolhandler, S. (2009). Medical bankruptcy in the United States, 2007: Results of a national study. American Journal of Medicine, 122(8), 741-746.

Huang, N., Yip, W., Chang, H. J., \& Chou, Y. J. (2006). Trends in rural and urban differentials in incidence rates for ruptured appendicitis under the National Health Insurance in Taiwan. Public Health, 120(11), 1055-1063. 
Karaca-Mandic, P., Jena, A. B., Joyce, G. F., \& Goldman, D.P. (2012). Out-of-pocket medication costs and use of medications and health care services among children with asthma. JAMA, 307(12), 1284-1291.

Khan, A., \& Zaman, S. (2010). Costs of vaginal delivery and Caesarean section at a tertiary level public hospital in Islamabad, Pakistan. BMC Pregnancy and Childbirth, 10, 2.

Kruk, M. E., Mbaruku, G., Rockers, P. C., \& Galea, S. (2008). User fee exemptions are not enough: out-of-pocket payments for 'free' delivery services in rural Tanzania. Tropical Medicine and International Health, 13(12), 1442-1451.

Kullgren, J. T., Galbraith, A. A., Hinrichsen, V. L., Miroshnik, I., Penfold, R. B., Rosenthal, M. B., ... Lieu, T. A. (2010). Health care use and decision making among lower-income families in high-deductible health plans. Archives of Internal Medicine, 170(21), 1918-1925.

LeFevre, A. E., Shillcutt, S. D., Waters, H. R., Haider, S., El Arifeen, S., Mannan, I., ... Projahnmo Study Group. (2013). Economic evaluation of neonatal care packages in a clusterrandomized controlled trial in Sylhet, Bangladesh. Bulletin of the World Health Organization, 91(10), 736-745.

Leone, T., James, K. S., \& Padmadas, S. S. (2013). The burden of maternal health care expenditure in India: Multilevel analysis of national data. Maternal and Child Health Journal, 17(9), $1622-1630$.

Liabsuetrakul, T., \& Oumudee, N. (2011). Effect of health insurance on delivery care utilization and perceived delays and barriers among southern Thai women. BMC Public Health, 11, 510.

Liljestrand, J., \& Sambath, M. R. (2012). Socio-economic improvements and health system strengthening of maternity care are contributing to maternal mortality reduction in Cambodia. Reproductive Health Matters, 20(39), 62-72.

Long, Q., Zhang, T., Xu, L., Tang, S., \& Hemminki, E. (2010). Utilisation of maternal health care in western rural China under a new rural health insurance system (New Co-operative Medical System). Tropical Medicine and International Health, 15(10), 1210-1217.

Lopes Gde Jr, L., de Souza, J. A. \& Barrios, C. (2013). Access to cancer medications in low- and middle-income countries. Nature Reviews Clinical Oncology, 10(6), 314-322.

Mossialos, E., Wenzl, M., Osborn, R., \& Anderson, C. (2015). 2014 International profiles of health care systems. New York, NY, U.S.A: The Commonwealth Fund. Retrieved from: http://www.commonwealthfund.org/ /media/files/publications/fund-report/2015/jan/ 1802_mossialos_intl_profiles_2014_v7.pdf

Muldoon, K. A., Galway, L. P., Nakajima, M., Kanters, S., Hogg, R.S., Bendavid, E., \& Mills, E. J. (2011). Health system determinants of infant, child and maternal mortality: A cross-sectional study of UN member countries. Globalization and Health, 7, 42.

Nguyen, H. T., Hatt, L., Islam, M., Sloan, N. L., Chowdhury, J., Schmidt, J. O., ... Wang, H. (2012). Encouraging maternal health service utilization: An evaluation of the Bangladesh voucher program. Social Science and Medicine, 74(7), 989-996.

Odeyemi, I. A., \& Nixon J. (2013). Assessing equity in health care through the national health insurance schemes of Nigeria and Ghana: a review-based comparative analysis. International Journal for Equity in Health, 12, 9.

Onwujekwe, O., Hanson, K., Uzochukwu, B., Ichoku, H., Ike, E., \& Onwughalu, B. (2010). Are malaria treatment expenditures catastrophic to different socio-economic and geographic groups and how do they cope with payment? A study in southeast Nigeria. Tropical Medicine and International Health, 15(1), 18-25.

Ortega-Sanchez, I. R., Molinari, N. A., Fairbrother, G., Szilagyi, P. G., Edwards, K. M., Griffin, M. R., ... Staat, M. A. (2012). Indirect, out-of-pocket and medical costs from influenzarelated illness in young children. Vaccine, 30(28), 4175-4181. 
Perkins, M., Brazier, E., Themmen, E., Bassane, B., Diallo, D., Mutunga, A., ... Ngobola, O. (2009). Out-of-pocket costs for facility-based maternity care in three African countries. Health Policy and Planning, 24(4), 289-300.

Raz, R., Lerner-Geva, L., Leon, O., Chodick, G., \& Gabis, L. V. (2013). A survey of out-of-pocket expenditures for children with autism spectrum disorder in Israel. Journal of Autism and Developmental Disorders, 43(10), 2295-2302.

Saksena, P., Reyburn, H., Njau, B., Chonya, S., Mbakilwa, H., \& Mills, A. (2010). Patient costs for paediatric hospital admissions in Tanzania: a neglected burden? Health Policy and Planning, 25(4), 328-333.

Sonneveldt, E., DeCormier Plosky, W., \& Stover, J. (2013). Linking high parity and maternal and child mortality: what is the impact of lower health services coverage among higher order births? BMC Public Health, 13(Suppl 3), S7.

Spaan, E., Mathijssen, J., Tromp, N., McBain, F., ten Have, A. \& Baltussen, R. (2012). The impact of health insurance in Africa and Asia: a systematic review. Bulletin of the World Health Organization, 90(9), 685-692.

Sreeramareddy, C. T., Sathyanarayana, T. N., \& Kumar, H. N. (2012) Utilization of health care services for childhood morbidity and associated factors in India: a national cross-sectional household survey. PLOS One, 7(12), e51904.

Srivastava, N. M., Awasthi, S., \& Agarwal, G. G. (2009). Care-seeking behavior and out-ofpocket expenditure for sick newborns among urban poor in Lucknow, northern India: a prospective follow-up study. BMC Health Services Research, 9, 61.

Tsimicalis, A., Stevens, B., Ungar, W. J., McKeever, P., Greenberg, M., Agha, M., ... Barr, R. (2013). A mixed method approach to describe the out-of-pocket expenses incurred by families of children with cancer. Pediatric Blood and Cancer, 60(3), 438-445.

World Bank. (2013). World Development Indicators. Washington, DC, U.S.A. Retrieved from: http://data.worldbank.org/data-catalog/world-development-indicators/

World Bank. (2014). Updated Income Classifications. Washington, DC, U.S.A. Retrieved from: http://data.worldbank.org/news/2015-country-classifications

World Bank. (2016). Health expenditure, public (\% of total health expenditure). Washington, DC, U.S.A. Retrieved from:http://data.worldbank.org/indicator/SH.XPD.PUBL

World Health Organization. (2010). Health Systems Financing: The path to universal coverage. Geneva, Switzerland. Retrieved from: http://www.who.int/whr/2010/10_summary_en. pdf?ua $=1$.

World Health Organization. (2012). General statistical procedures used to construct WHO health expenditure database. Geneva, Switzerland. Retrieved from: http://www.who.int/nha/expendi ture_database/estimation.pdf

World Health Organization. (2012). Global Health Expenditure Database. Geneva, Switzerland. Retrieved from: http://www.who.int/nha/expenditure_database/en/

World Health Organization. (2012). Newborns: reducing mortality. Geneva, Switzerland. Retrieved from: http://www.who.int/mediacentre/factsheets/fs333/en/

World Health Organization. (2014). Children: reducing mortality. Geneva, Switzerland. Retrieved from: http://www.who.int/mediacentre/factsheets/fs178/en/

World Health Organization. (2014). Trends in Maternal Mortality: 1990 to 2013. Geneva, Switzerland. Retrieved from: http://apps.who.int/iris/bitstream/10665/112697/1/WHO_RH R_14.13_eng.pdf

World Health Organization, \& United Nations Children's Fund. (2005). GIVS Global Immunization Vision and Strategy 2005-2015. Geneva, Switzerland \& New York, NY, U.S.A. Retrieved from: http://apps.who.int/iris/bitstream/10665/69146/1/WHO_IVB_05.05.pdf

Yuan, B., Qian, X., \& Thomsen, S. (2013). Disadvantaged populations in maternal health in China who and why? Global Health Action, 6, 19542. 